\title{
INFLUÊNCIA DO EL NIÑO E LA NIÑA NA PRECIPITAÇÃO MÁXIMA DIÁRIA DO ESTADO DE GOIÁS
}

\author{
FRANCISCO FERNANDO NORONHA MARCUZZO'; ${ }^{1}$ VANESSA ROMERO²
}

\author{
${ }^{1} \mathrm{CPRM} / \mathrm{SGB}$ - Serviço Geológico do Brasil, Porto Alegre, RS, Brasil \\ ${ }^{2}$ Instituto Federal de Educação, Ciência e Tecnologia de Goiás (IFG), Goiânia, GO, Brasil \\ francisco.marcuzzo@cprm.gov.br, vromero.fe@gmail.com
}

Recebido Novembro de 2011 - Aceito Maio de 2013

\begin{abstract}
RESUMO
O objetivo deste trabalho foi investigar a correlação entre ENOS e a precipitação máxima diária mensal e anual no Estado de Goiás, de 1977 a 2006, utilizando-se dados do Serviço Climatológico Nacional dos Estados Unidos (NOAA). Gráficos de dispersão foram confeccionados mediante cálculos estatísticos para delinear a influência dos eventos de $\mathrm{El}$ (La) Niño(a) nas chuvas máximas diárias de Goiás durante a série histórica mensal, utilizando-se 88 estações com 30 anos de dados e 26 estações com 20 a 29 anos de dados. A fase mais intensa de La Niña, para o período de 1977 a 2006, registrou queda na temperatura oceânica equivalente a $1,9^{\circ} \mathrm{C}$ em 1988 , ocasionando uma precipitação máxima diária de 59,6 mm em Goiás. O episódio mais intenso do El Niño, durante a série histórica, ocorreu no ano de 1997 (a temperatura do oceano Pacífico aumentou 2,5 ${ }^{\circ}$ ) e ocasionou uma precipitação máxima diária de $68,1 \mathrm{~mm}$. Conclui-se com este estudo que a maior e a menor precipitação máxima diária anual, registrada para o Estado de Goiás no período de 1977 a 2006, foram de 461,3 mm (1997) e $360,3 \mathrm{~mm}$ (2003), respectivamente, e ocorreram em anos do El Niño moderado $\left(1,3^{\circ} \mathrm{C}\right)$ e fraco $\left(0,5^{\circ} \mathrm{C}\right)$. Palavras-chave: Chuva máxima diária, temperatura do oceano Pacífico, ENOS.
\end{abstract}

\begin{abstract}
EFFECTS OF EL NIÑO AND LA NIÑA IN MAXIMUM DAILY PRECIPITATION OF THE STATE GOIÁS

The objective of this study was to investigate the correlation between ENSO and the maximum annual and daily precipitation over the State of Goiás, from 1977 to 2006, using data from National Weather Service of the United States (NOAA). Scatter plots were made by statistical calculations to delineate the influence of El (La) Niño (a) events on maximum daily rainfall over Goiás using the monthly series, from 88 gauge stations with 30 years of data and 26 stations with 20 to 29 years of data. The most intense phase of La Niña, for the period 1977 to 2006, recorded an ocean temperature decrease equivalent to $1.9^{\circ} \mathrm{C}$ in 1988 , resulting in a maximum daily rainfall of $59.6 \mathrm{~mm}$ in Goiás The episode of the most intense El Niño during the series occurred in the year 1997 (Pacific ocean temperature increased $2.5^{\circ} \mathrm{C}$ ) and caused a maximum daily rainfall of $68.1 \mathrm{~mm}$. It is concluded from this study that the highest and lowest maximum daily precipitation recorded for the State of Goiás, in the period 1977 to 2006, were $461.3 \mathrm{~mm}$ (1997) and $360.3 \mathrm{~mm}$ (2003), respectively, and occurred in years of moderate El Nino $\left(1.3^{\circ} \mathrm{C}\right)$ and weak $\left(0.5^{\circ} \mathrm{C}\right)$ El Niño.
\end{abstract}

Keywords: Maximum Daily Rainfall, temperature of the Pacific Ocean, ENSO. 


\section{INTRODUÇÃO}

As tendências dos eventos extremos de precipitação estão associadas às anomalias de temperatura registradas em porções específicas do oceano Pacífico, provocando o aquecimento superficial das águas do Pacífico Equatorial ou o resfriamento, respectivamente denominados El Niño e La Niña. As alterações do comportamento climático, intensidade dos ventos alísios, precipitação, secas, cheias e frentes frias que atingem o centro-sul brasileiro, o nordeste, e também a região norte, representam o cenário que o El Niño e a La Niña podem promover.

Estudo realizado por Pereira et al. (2010) sobre a pluviometria no estado de Goiás, aplicando a técnica de análise fatorial em componentes principais, revela que a estação chuvosa de Goiás está associada à ocorrência das Zonas de Convergência do Atlântico Sul (ZCAS), que atuam com mais frequência nos meses de dezembro, janeiro e fevereiro. Sales et al. (2010) em estudo sobre "cheias e secas no Amazonas, e as influências dos fenômenos climáticos El Niño, La Niña, ODP e OMA", concluíram que embora não sejam determinantes, estes eventos tem uma grande influência na ocorrência de cheias ou secas, extraordinárias no sistema Rio Negro/Solimões. Sousa et al. (2010) verificaram em seu estudo sobre Oscilação Decadal do Pacífico (ODP) e sua influência na Precipitação de Goiânia/GO, que a variabilidade da precipitação neste município apresenta grande influência da ODP, uma vez que ficou evidente a perfeita relação direta entre a redução nos totais anuais de PRP (precipitação) e na frequência de dias com precipitação durante a fase fria da ODP, assim como aumento na precipitação anual e frequência de dias com chuva durante a sua fase quente.

O objetivo deste estudo foi investigar a dispersão temporal, correlação e influência da variação da temperatura no oceano Pacífico na precipitação máxima diária do estado de Goiás, entre os anos de 1977 a 2006.

\section{MATERIAL E MÉTODOS}

\section{1 - Caracterização da área de estudo e dados utilizados}

O estado de Goiás localiza-se na região centro-oeste do Brasil (Figura 1), no Planalto Central, e possui uma área de $340.103,467 \mathrm{~km}^{2}$ (IBGE, 2010). Está delimitado pelos estados do Tocantins (norte), Bahia (nordeste), Minas Gerais (Sudeste e Sul), Mato Grosso do Sul (Sul e Sudoeste), Mato Grosso (Oeste e Noroeste) e pelo Distrito Federal.

O uso do solo em Goiás está mais concentrado em atividades pecuaristas (Figura 1). Utilizou-se neste estudo 114 estações pluviométricas (Figura 1), cujos dados diários de precipitação pluvial máxima diária foram obtidos da Rede Hidrometeorológica Nacional da Agência Nacional de Águas

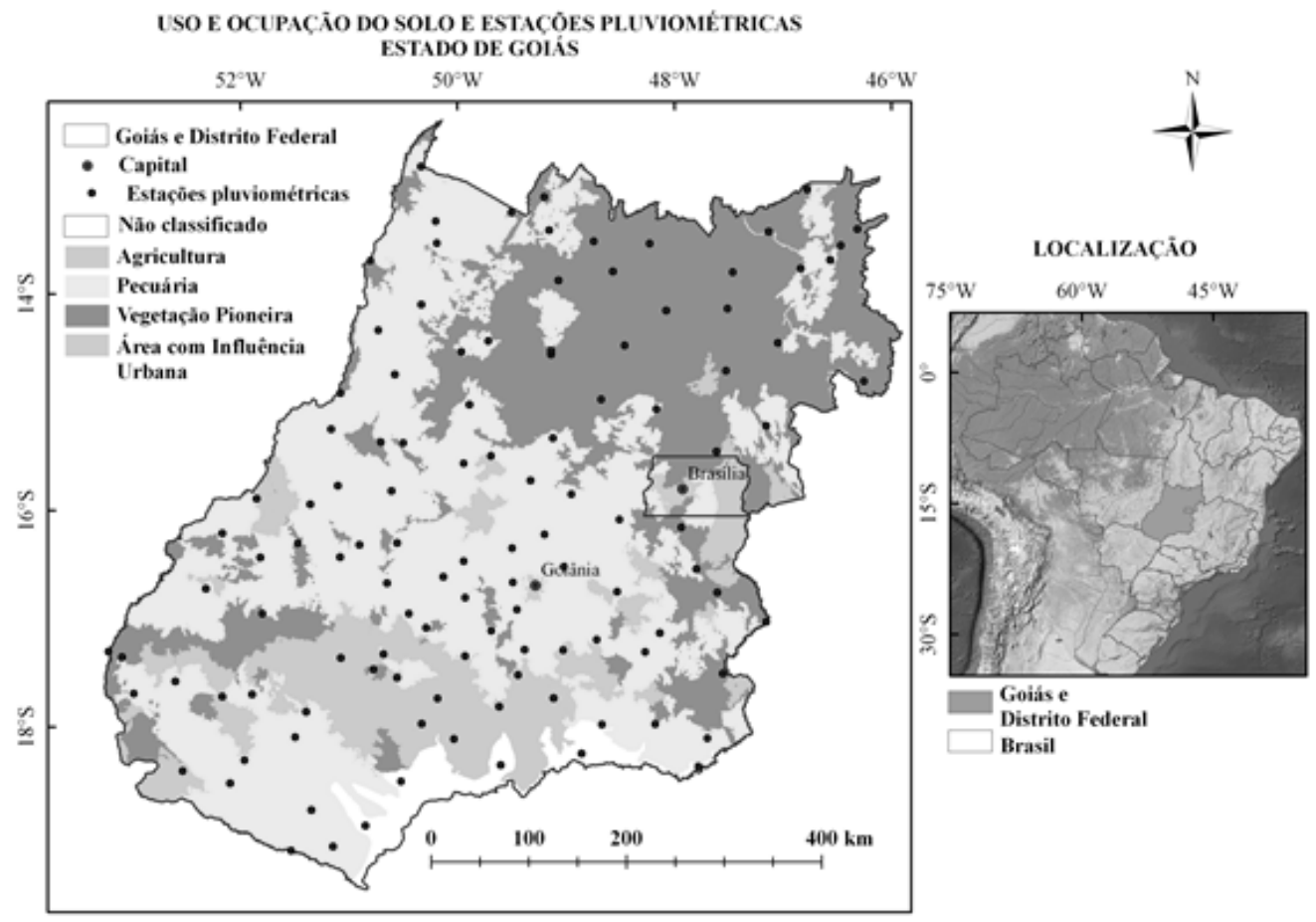

Figura 1 - Localização das estações pluviométricas e sua inserção no uso e ocupação do solo e a localização do estado de Goiás. 
(ANA) e da CPRM/SGB (Companhia de Pesquisa de Recursos Minerais / Serviço Geológico do Brasil); sendo 88 estações com 30 anos de dados e 26 estações com 20 a 29 anos de dados (Pinto et al., 2011). Estes dados diários de precipitação pluvial máxima diária foram compilados, consistidos, organizados e tratados estatisticamente, com informação diária, mensal, anual e sazonal.

O ION (Índice Oceânico Niño(a)) é um índice que identifica as anomalias da superfície do oceano Pacífico através de uma média móvel de três meses (Tabela 1). Quando o ION for maior que $+0,5^{\circ} \mathrm{C}$ por no mínimo cinco meses consecutivos, o período é caracterizado como El Niño, e quando o índice for menor do que $-0,5^{\circ} \mathrm{C}$ por no mínimo cinco meses consecutivos, o período é caracterizado como La Niña.

Os dados de intensidade dos fenômenos El Niño e La Niña (Tabela 2) foram obtidos do Serviço Climatológico Nacional dos Estados Unidos (NOAA - National Weather Service), onde os valores em negrito correspondem ao El Niño (positivo) e La Niña (negativo).

Neste trabalho utilizou-se dados do projeto SRTM (Shuttle Radar Topology Mission) com resolução de 90 metros. As imagens SRTM foram agrupadas em um programa GIS (Geographic Information System) e posteriormente o MDE (Modelo Digital de Elevação) foi delimitado, permitindo analisar a hipsometria do estado de Goiás, que se caracteriza por terras cujas altitudes variam de 178 a 1667 metros, resultando num gradiente altimétrico de 1489 metros. As terras mais altas de Goiás localizam-se na região do Distrito Federal e proximidades (Figura 2). Em sua maior parte, Goiás encontra-se inserido no bioma do cerrado, pequena parte do estado está inserida na mata atlântica (Figura 2).

Com uma população de 6.003 .788 habitantes e 246 municípios, o estado de Goiás possui baixa densidade demográfica sendo a cidade mais densa do estado, a capital, Goiânia, com aproximadamente 103 hab. $\left(\mathrm{km}^{2}\right)^{-1}$. O município de menor densidade demográfica é Aporé (Figura 3) com aproximadamente 1 hab. $\left(\mathrm{km}^{2}\right)^{-1}$ (IBGE, 2010). Segundo a classificação climática de Köppen, existem três climas atuantes no estado: o clima tropical com estação seca no inverno (Aw), o clima temperado úmido com inverno seco e verão quente
(Cwa) e o clima temperado úmido com inverno seco e verão temperado (Cwb) (Figura 3).

\subsection{Regressão linear e polinomial}

São métodos para se estimar a condicional de uma variável $Y$, dados os valores de algumas outras variáveis $X$. A regressão, em geral, trata da questão de se estimar um valor condicional esperado. Em muitas situações, uma relação linear pode ser válida para sumarizar a associação entre as variáveis $Y$ e $X$. Já a regressão polinomial tende a descrever o caminhamento da evolução da variável dependente $Y$ conforme as modificações da variável $X$. As regressões linear e polinomial são, respectivamente, descritas como:

$$
\begin{aligned}
& Y=\beta_{0}+\beta_{1} X \\
& Y=\beta_{6} X^{6}+\beta_{5} X^{5}+\cdots+\beta_{1} X+\beta_{0}
\end{aligned}
$$

em que, $Y$ é a variável linear dependente; $\beta_{6}, \beta_{5}, \ldots, \beta_{1}$, e $\beta_{0}$ são os coeficientes da regressão; $X$ é a variável independente.

\subsection{Verificação estatística descritiva}

Através da estatística descritiva, pode-se ter as características essenciais para a formação de histograma de frequências relativas de uma amostra de dados hidrológicos (Naghettini e Pinto, 2007). Para este estudo foram calculadas as seguintes medidas de tendência central e de dispersão.

\section{i. Medidas de tendências central}

A média é a medida de posição mais frequentemente usada e tem um significado teórico importante na estimativa de amostras. É calculada pela seguinte fórmula:

$$
\bar{X}=\frac{X_{1}, \ldots, X_{n}}{N}=\frac{1}{N} \sum_{i=0}^{n} X_{i}
$$

em que, $\bar{X}$ é a média; $N$ é o tamanho da amostra e $X_{i}$ até $X_{n}$ são os somatórios da amostra.

A mediana é uma outra medida de posição mais resistente do que a média, por ser imune à eventual presença de valores extremos discordantes na amostra. É calculada pela equação:

Tabela 1 - Classificação da intensidade do Índice Oceânico Niño(a).

\begin{tabular}{|c|c|c|}
\hline Evento & Índice Oceânico Niño(a) & Intensidade \\
\hline \hline \multirow{3}{*}{ El Niño } & 0,5 a 0,9 & Fraca \\
& 1,0 a 1,4 & Moderada \\
& $\geq 1,5$ & Forte \\
\hline \multirow{3}{*}{ La Niña } & $-0,5$ a $-0,9$ & Fraca \\
& $-1,0$ a $-1,4$ & Moderada \\
& $\leq-1,5$ & Forte \\
\hline
\end{tabular}


Tabela 2 - Intensidade do El Niño e de La Niña durante o período de 1977 a 2006.

\begin{tabular}{|c|c|c|c|c|c|c|c|c|c|c|c|c|c|}
\hline \multirow{2}{*}{ Ano } & \multicolumn{12}{|c|}{ Índice Niño no Oceano Pacífico } & \multirow{2}{*}{ Média } \\
\hline & DJF & JFM & FMA & MAM & AMJ & MJJ & JJA & JAS & ASO & SON & OND & NDJ & \\
\hline 1977 & $\overline{0,6}$ & $\mathbf{0 , 5}$ & 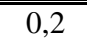 & 0,2 & 0,2 & 0,4 & 0,4 & 0,4 & $\mathbf{0 , 5}$ & 0,6 & 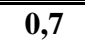 & $\overline{0,7}$ & 0,5 \\
\hline 1978 & $\mathbf{0 , 7}$ & 0,4 & 0 & $-0,3$ & $-0,4$ & $-0,4$ & $-0,4$ & $-0,4$ & $-0,4$ & $-0,3$ & $-0,2$ & $-0,1$ & $-0,2$ \\
\hline 1979 & $-0,1$ & 0 & 0,1 & 0,1 & 0,1 & $-0,1$ & 0 & 0,1 & 0,3 & 0,4 & 0,5 & 0,5 & 0,2 \\
\hline 1980 & 0,5 & 0,3 & 0,2 & 0,2 & & 0,3 & 0,2 & 0 & $-0,1$ & $-0,1$ & 0 & $-0,1$ & 0,1 \\
\hline 1981 & $-0,3$ & $-0,5$ & $-0,5$ & $-0,4$ & $-0,3$ & $-0,3$ & $-0,4$ & $-0,4$ & $-0,3$ & $-0,2$ & $-0,1$ & $-0,1$ & $-0,3$ \\
\hline 1982 & 0 & 0,1 & 0,1 & 0,3 & 0,6 & 0,7 & 0,7 & 1 & 1,5 & 1,9 & 2,2 & 2,3 & 1,0 \\
\hline 1983 & 2,3 & 2 & 1,5 & 1,2 & 1 & 0,6 & 0,2 & $-0,2$ & $-0,6$ & $-0,8$ & $-0,9$ & $-0,7$ & 0,5 \\
\hline 1984 & $-0,4$ & $-0,2$ & $-0,2$ & $-0,3$ & $-0,5$ & $-0,4$ & $-0,3$ & $-0,2$ & $-0,3$ & $-0,6$ & $-0,9$ & $-1,1$ & $-0,5$ \\
\hline 1985 & $-0,9$ & $-0,8$ & $-0,7$ & $-0,7$ & $-0,7$ & $-0,6$ & $-0,5$ & $-0,5$ & $-0,5$ & $-0,4$ & $-0,3$ & $-0,4$ & $-0,6$ \\
\hline 1986 & $-0,5$ & $-0,4$ & $-0,2$ & $-0,2$ & $-0,1$ & 0 & 0,3 & 0,5 & 0,7 & 0,9 & 1,1 & 1,2 & 0,3 \\
\hline 1987 & 1,2 & 1,3 & 1,2 & 1,1 & 1 & 1,2 & 1,4 & 1,6 & 1,6 & 1,5 & 1,3 & 1,1 & 1,3 \\
\hline 1988 & $\mathbf{0 , 7}$ & 0,5 & 0,1 & $-0,2$ & $-0,7$ & $-1,2$ & $-1,3$ & $-1,2$ & $-1,3$ & $-1,6$ & $-1,9$ & $-1,9$ & $-0,8$ \\
\hline 1989 & $-1,7$ & $-1,5$ & $-1,1$ & $-0,8$ & $-0,6$ & $-0,4$ & $-0,3$ & $-0,3$ & $-0,3$ & $-0,3$ & $-0,2$ & $-0,1$ & $-0,6$ \\
\hline 1990 & 0,1 & 0,2 & 0,2 & 0,2 & 0,2 & 0,2 & 0,3 & 0,3 & 0,3 & 0,3 & 0,3 & 0,4 & 0,3 \\
\hline 1991 & 0,4 & 0,3 & 0,3 & 0,4 & 0,6 & $\mathbf{0 , 8}$ & 1 & 0,9 & 0,9 & 1 & 1,4 & 1,6 & 0,8 \\
\hline 1992 & 1,8 & 1,6 & 1,5 & 1,4 & 1,2 & 0,8 & 0,5 & 0,2 & 0 & $-0,1$ & 0 & 0,2 & 0,8 \\
\hline 1993 & 0,3 & 0,4 & 0,6 & 0,7 & 0,8 & 0,7 & 0,4 & 0,4 & 0,4 & 0,4 & 0,3 & 0,2 & 0,5 \\
\hline 1994 & 0,2 & 0,2 & 0,3 & 0,4 & 0,5 & 0,5 & 0,6 & 0,6 & 0,7 & $\mathbf{0 , 9}$ & 1,2 & 1,3 & 0,6 \\
\hline 1995 & 1,2 & 0,9 & 0,7 & 0,4 & 0,3 & 0,2 & 0 & $-0,2$ & $-0,5$ & $-0,6$ & $-0,7$ & $-0,7$ & 0,1 \\
\hline 1996 & $-0,7$ & $-0,7$ & $-0,5$ & $-0,3$ & $-0,1$ & $-0,1$ & 0 & $-0,1$ & $-0,1$ & $-0,2$ & $-0,3$ & $-0,4$ & $-0,3$ \\
\hline 1997 & $-0,4$ & $-0,3$ & 0 & 0,4 & 0,8 & 1,3 & 1,7 & 2 & 2,2 & 2,4 & 2,5 & 2,5 & 1,3 \\
\hline 1998 & 2,3 & 1,9 & 1,5 & 1 & 0,5 & 0 & $-0,5$ & $-0,8$ & -1 & $-1,1$ & $-1,3$ & $-1,4$ & 0,1 \\
\hline 1999 & $-1,4$ & $-1,2$ & $-0,9$ & $-0,8$ & $-0,8$ & $-0,8$ & $-0,9$ & $-0,9$ & -1 & $-1,1$ & $-1,3$ & $-1,6$ & $-1,1$ \\
\hline 2000 & $-1,6$ & $-1,4$ & -1 & & $-0,6$ & $-0,5$ & $-0,4$ & $-0,4$ & $-0,4$ & $-0,5$ & $-0,6$ & $-0,7$ & $-0,7$ \\
\hline 2001 & $-0,6$ & $-0,5$ & $-0,4$ & $-0,2$ & $-0,1$ & 0,1 & 0,2 & 0,2 & 0,1 & 0 & $-0,1$ & $-0,1$ & $-0,1$ \\
\hline 2002 & $-0,1$ & 0,1 & 0,2 & 0,4 & $\mathbf{0 , 7}$ & $\mathbf{0 , 8}$ & 0,9 & 1 & 1,1 & 1,3 & 1,5 & 1,4 & 0,8 \\
\hline 2003 & 1,2 & $\mathbf{0 , 9}$ & 0,5 & 0,1 & $-0,1$ & 0,1 & 0,4 & 0,5 & 0,6 & 0,5 & 0,6 & 0,4 & 0,5 \\
\hline 2004 & 0,4 & 0,3 & 0,2 & 0,2 & 0,3 & 0,5 & 0,7 & 0,8 & 0,9 & $\mathbf{0 , 8}$ & $\mathbf{0 , 8}$ & 0,8 & 0,6 \\
\hline 2005 & 0,7 & 0,5 & 0,4 & 0,4 & 0,4 & 0,4 & 0,4 & 0,3 & 0,2 & $-0,1$ & $-0,4$ & $-0,7$ & 0,2 \\
\hline 2006 & $-0,7$ & $-0,6$ & $-0,4$ & $-0,1$ & 0,1 & 0,2 & 0,3 & 0,5 & 0,6 & 0,9 & 1,1 & 1,1 & 0,3 \\
\hline
\end{tabular}

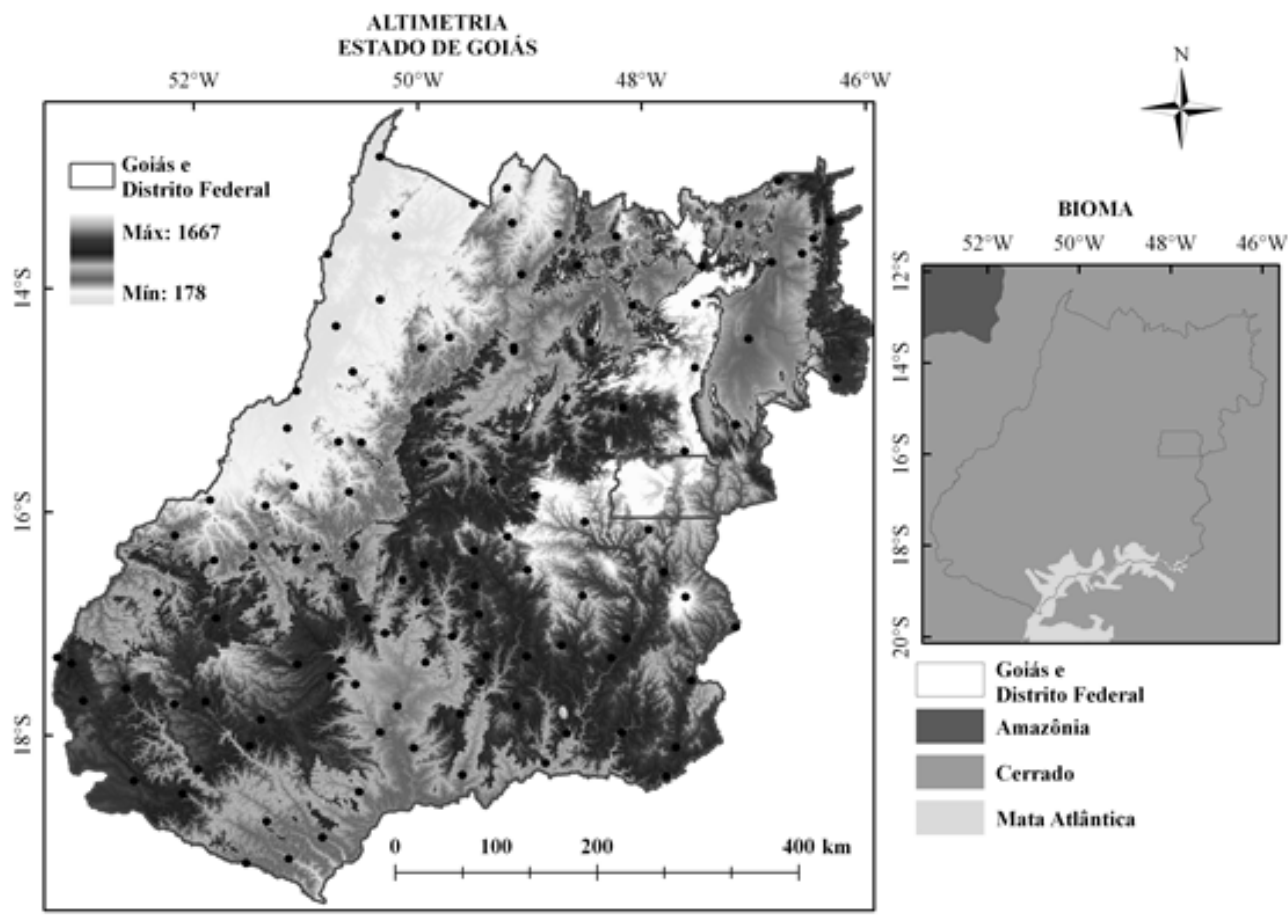

Figura 2 - Localização das estações pluviométricas na altimetria e bioma do estado de Goiás. 


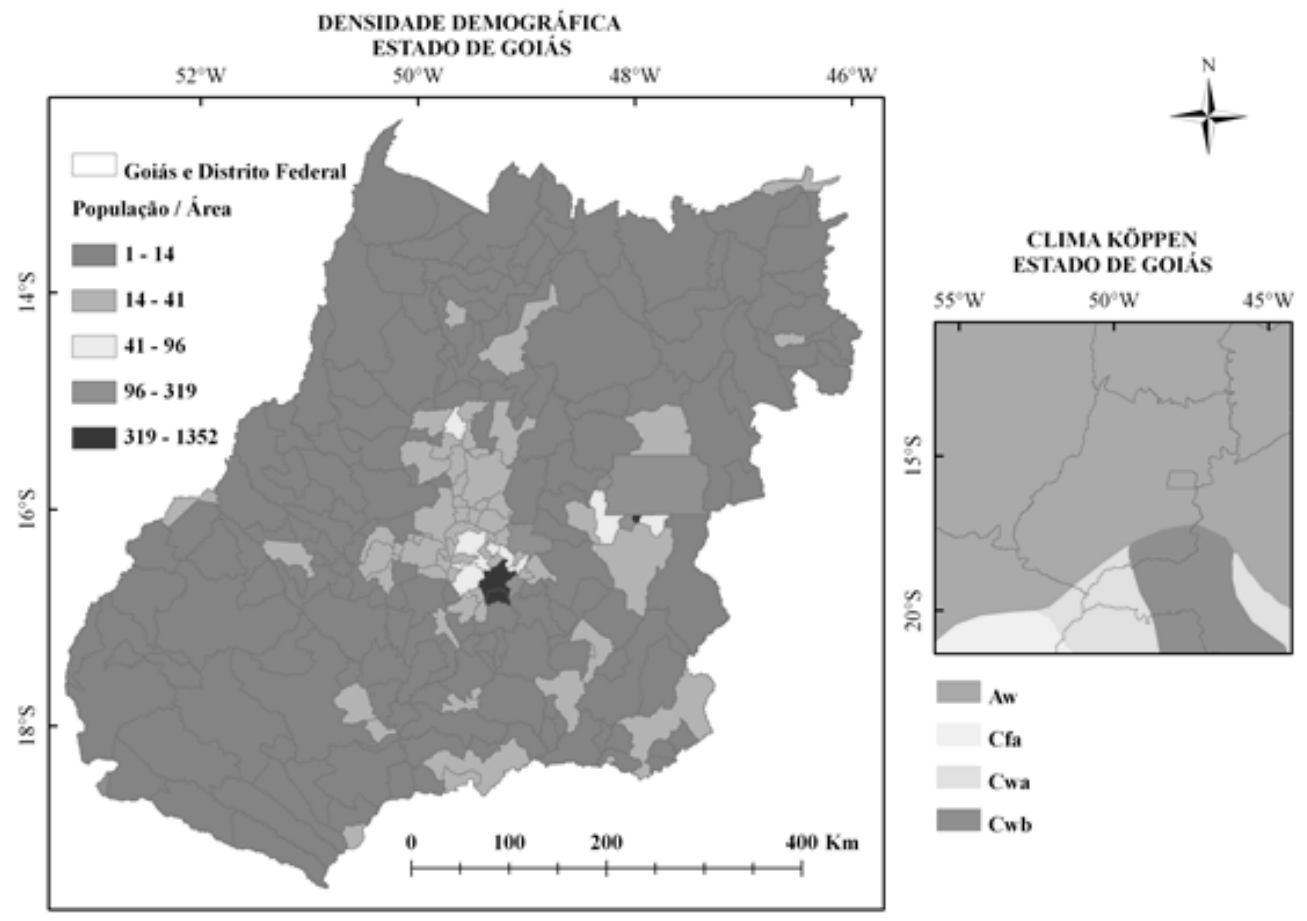

Figura 3 - Densidade demográfica e clima (classificação de Köppen) do estado de Goiás.

$$
X_{\text {med }}=\frac{X_{\frac{N}{2}}+X_{\left(\frac{N}{2}+1\right)}}{2}
$$

em que, $X_{\text {med }}$ é a mediana; $N$ é o tamanho da amostra e $X$ é a posição da amostra.

\section{ii. Medidas de dispersão}

O desvio padrão é fortemente influenciado pelos menores e maiores desvios, constituindo-se na medida de dispersão mais frequentemente usada em analise estatística de fenômenos hidrometeorológicos. É calculado pela seguinte expressão:

$$
S=\frac{1}{N-1} \sum_{i=0}^{n}\left(X_{i}-\bar{X}\right)^{2}
$$

em que, $N$ é o tamanho da amostra; $X_{i}$ é o valor de cada amostra e $\bar{X}$ é a média.

Utilizando-se as medidas de tendência central e de dispersão podem-se verificar analiticamente os parâmetros, e observar se as amostras são diferentes ou semelhantes.

\section{RESULTADOS E DISCUSSÃO}

Os fenômenos El Niño e La Niña exercem um papel relevante nas anomalias de distribuição temporal de precipitação pluviométrica máxima diária ocasionando, respectivamente, o aumento ou a diminuição da precipitação em períodos de variação acentuada na temperatura média do oceano Pacífico.
Conforme demonstra a Figura 4, nos meses de janeiro de 1977 a 2006 houve uma tendência de diminuição da precipitação em Goiás durante os episódios de resfriamento das águas oceânicas do Pacífico. Na fase mais intensa de La Niña para os meses de janeiro, do período histórico de 1977 a 2006, a temperatura oceânica diminuiu $1,7{ }^{\circ} \mathrm{C}$ (1989), ocasionando uma precipitação máxima diária de $50,1 \mathrm{~mm}$ em Goiás. Em períodos do El Niño a temperatura oceânica aumentou até 2,3 ${ }^{\circ} \mathrm{C}$, ocasionando uma precipitação máxima diária de 69,2 mm. Na Figura 4, observa-se que há uma tendência média de aumento na precipitação máxima diária para o mês de janeiro, quando o mesmo está sob influência do El Niño. A precipitação máxima diária obtida no período estudado foi de 70,7 mm (1985), para um valor de $-0,9$ de resfriamento das águas do Pacífico (La Niña). Já a menor precipitação diária, no mesmo período, foi de 48,7 mm (1998), para um El Niño de 2,3 ${ }^{\circ} \mathrm{C}$.

Durante os meses de fevereiro da série histórica de 1977 a 2006, diante do aumento das intensidades do La Niña e do El Niño, houve tendência de aumento da precipitação pluviométrica no estado de Goiás, de acordo com a Figura 5. Na fase mais forte de La Niña para os meses de fevereiro, do período histórico de 1977 a 2006, a temperatura do oceano Pacífico diminuiu até $1,5^{\circ} \mathrm{C}$ (1989) e provocou uma precipitação máxima diária no estado de Goiás de 50,2 mm. Já no episódio mais forte do El Niño, durante os anos de 1977 a 2006, a temperatura do oceano Pacífico aumentou até 2,0 


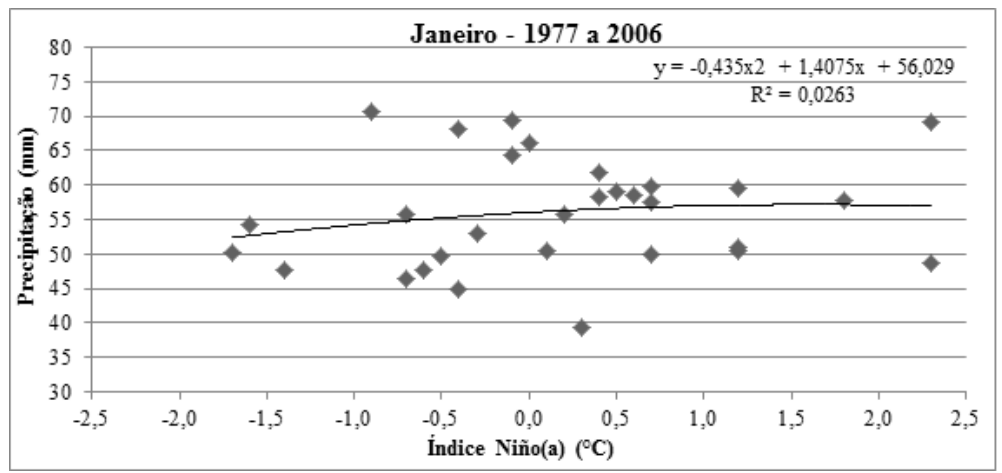

Figura 4 - Dispersão em janeiro da Precipitação Máxima Diária Média em relação ao Índice Niño(a) do período.

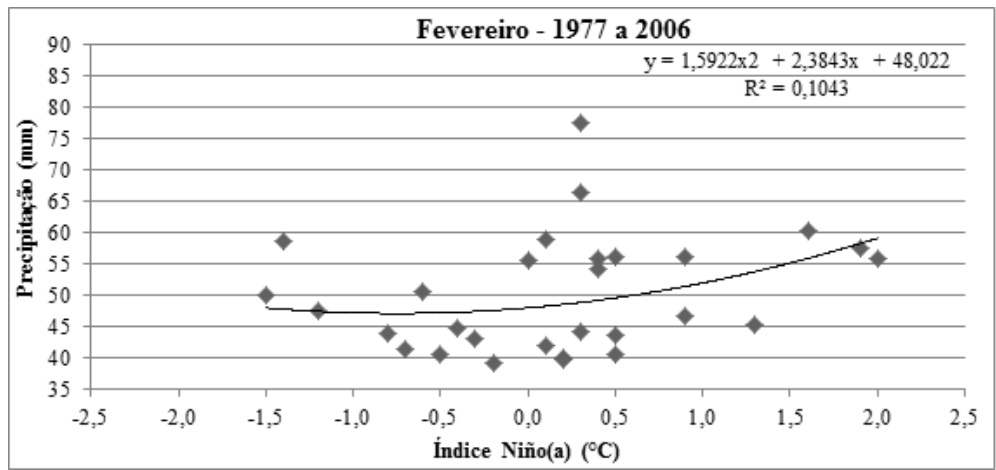

Figura 5 - Dispersão em fevereiro da Precipitação Máxima Diária Média em relação ao Índice Niño(a) do período.

${ }^{\circ} \mathrm{C}$, provocando uma precipitação máxima diária em Goiás de $55,9 \mathrm{~mm}$. De acordo com a Figura 5 nota-se uma tendência média de aumento da precipitação pluviométrica para fevereiro durante as fases do El Niño. Nas fases de La Niña há um ligeiro aumento da precipitação. A menor precipitação verificada para o período de estudo foi de 39,3 $\mathrm{mm}$ (1984), a maior foi de 77,6 mm (1980), e ambos eventos extremos ocorreram em períodos em que não registrou-se influência nem de La Niña e nem do El Niño.

Nos meses de março da série histórica utilizada neste estudo o resfriamento das águas do Pacífico (La Niña) provocou, durante suas ocorrências, aumento das chuvas em Goiás (Figura 6). A fase mais intensa deste fenômeno foi no ano de 1989 e a temperatura do oceano Pacífico diminuiu até $1,1^{\circ} \mathrm{C}$, provocando uma precipitação máxima diária de 50,6 mm. Nas fases do El Niño, de modo usual, a precipitação em Goiás aumentou (Figura 6). O maior aumento da temperatura das águas do oceano Pacífico, registrado nos meses de março da série de 1977 a 2006, foi de $1,5^{\circ} \mathrm{C}$ nos anos de 1983, 1992 e 1998, e provocou uma chuva máxima diária de $62,6 \mathrm{~mm}$. Observa-se na Figura 6, que tanto a máxima precipitação diária quanto a mínima registrada no período histórico desse estudo, 66,7 mm (1991) e 31,0 mm (1980), respectivamente, ocorreram em períodos normais, ou seja, períodos que não estavam sob influência dos Niños.
De acordo com a Figura 7, houve uma tendência de aumento da precipitação pluviométrica do estado de Goiás, no período de 1977 a 2006, durante as fases do El Niño. A maior diminuição da temperatura oceânica registrada durante o período considerado neste estudo foi de $0,8^{\circ} \mathrm{C}$ nos anos de 1989,1999 e 2000, acarretando uma precipitação máxima diária de 34,0 $\mathrm{mm}$, enquanto que nas fases do El Niño, o maior aumento foi de $1,4{ }^{\circ} \mathrm{C}$ em 1992 provocando uma chuva máxima diária de 44,5 mm. Durante os anos de 1977 a 2006, a maior precipitação registrada em Goiás foi de $50,9 \mathrm{~mm}$ para uma queda $0,1^{\circ} \mathrm{C}$ das águas do Pacífico e a menor, foi de 18,2 $\mathrm{mm}$ para um aumento normal de $0,4{ }^{\circ} \mathrm{C}$ da temperatura do oceano Pacífico.

Nos meses de maio de 1977 a 2006, houve uma tendência de diminuição da precipitação pluviométrica no estado de Goiás, tanto nos episódios de resfriamento das águas do Pacífico, quanto nas fases de aquecimento anormal. Na fase mais intensa de La Niña para os meses de maio, do período histórico de 1977 a 2006, a temperatura oceânica diminuiu até $0,8{ }^{\circ} \mathrm{C}$ (1999), ocasionando uma precipitação máxima diária de $15,3 \mathrm{~mm}$ em Goiás. Já em períodos do El Niño a temperatura oceânica aumentou até $1,2{ }^{\circ} \mathrm{C}$ (1992), ocasionando uma precipitação máxima diária de 11,2 mm. Observa-se que a precipitação máxima diária obtida no período histórico estudado foi de 37,9 mm (1982), para um valor de 0,6 de aquecimento das águas 


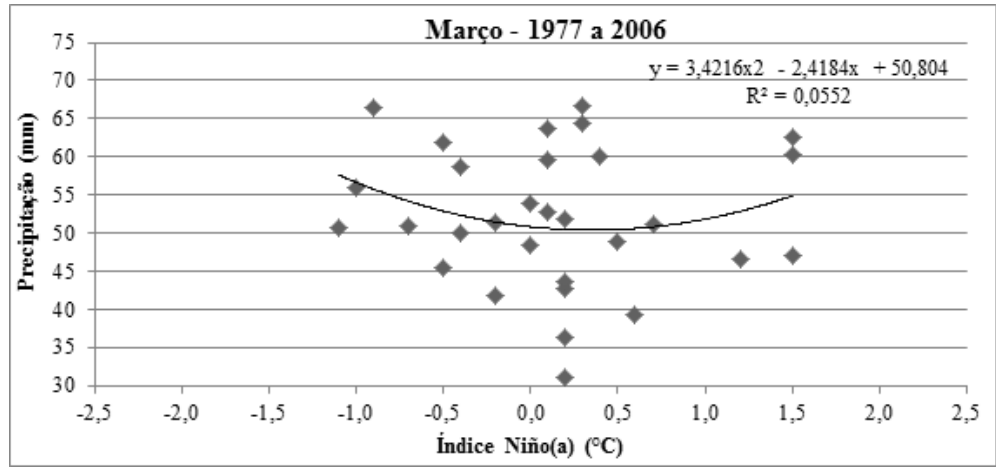

Figura 6- Dispersão em março da Precipitação Máxima Diária Média em relação ao Índice Niño(a) do período.

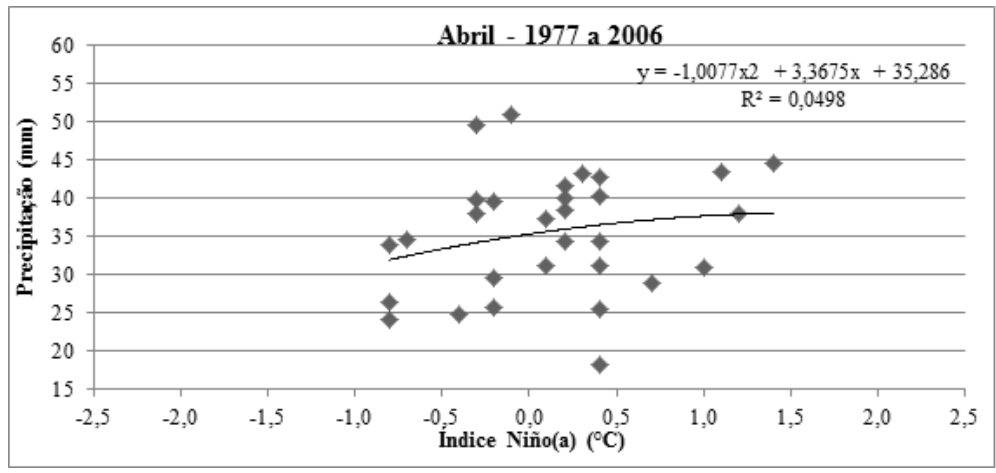

Figura 7 - Dispersão em abril da Precipitação Máxima Diária Média em relação ao Índice Niño(a) do período.

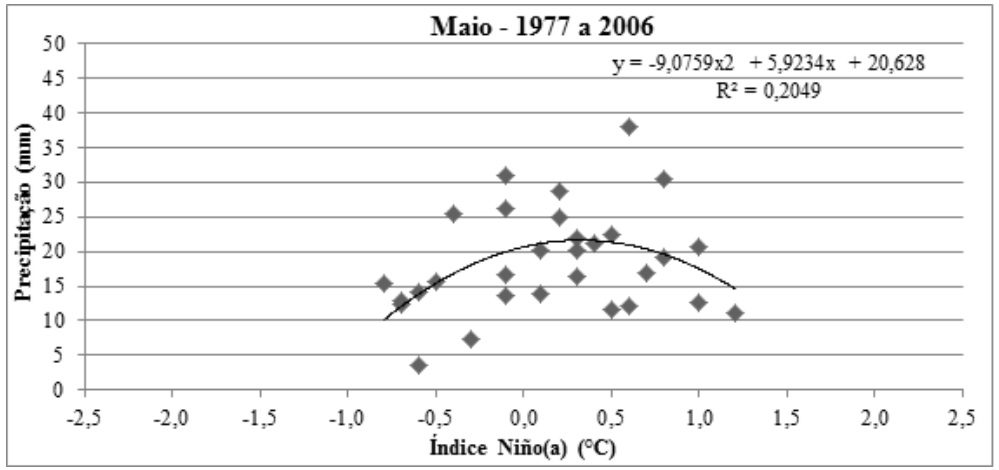

Figura 8 - Dispersão em maio da Precipitação Máxima Diária Média em relação ao Índice Niño(a) do período.

do oceano Pacífico (El Niño). Já a menor precipitação diária observada no mesmo período foi de 3,7 mm (2000), para um valor de La Niña de $-0,6^{\circ} \mathrm{C}$.

De acordo com a Figura 9, durante os meses de junho, de 1977 a 2006, houve tendência de aumento da precipitação pluviométrica no estado de Goiás. Na fase mais forte de La Niña para os meses de junho, do período histórico de 1977 a 2006, a temperatura do oceano Pacíico diminuiu $1,2{ }^{\circ} \mathrm{C}(1988)$ e provocou uma precipitação máxima diária no estado de Goiás de 7,5 mm. Já no episódio mais forte do El Niño durante o período histórico estudado a temperatura do oceano Pacífico aumentou $1,3{ }^{\circ} \mathrm{C}$, provocando uma precipitação máxima diária em Goiás de $39,1 \mathrm{~mm}$. A menor precipitação verificada para o período de estudo foi de $0,0 \mathrm{~mm}$ (1979 e 1984) em um período de temperatura normal do oceano Pacífico. Já a maior precipitação para os meses de junho de 1977 a 2006 foi de 39,1 mm (1997) e ocorreu na fase mais extrema do El Niño de toda a série considerada neste estudo.

De acordo com a Figura 10 nota-se uma tendência de diminuição da precipitação do estado de Goiás nos episódios do El Niño e La Niña registrados nos meses de julho de 1977 a 2006 . A ausência de chuvas em julho de 1988 caracteriza a fase mais forte de La Niña para o período em questão $\left(-1,3{ }^{\circ} \mathrm{C}\right)$, enquanto que na fase mais intensa do El Niño, o maior aumento da temperatura foi 
de $1,4^{\circ} \mathrm{C}$ no ano de 1992 provocando uma chuva máxima diária de 44,5 mm. Durante a série de julho de 1977 a 2006 a maior precipitação pluviométrica registrada em Goiás foi de $24,3 \mathrm{~mm}$ para um resfriamento das águas do Pacífico de $0,2^{\circ} \mathrm{C}$.

Na Figura 11 nota-se uma tendência de decréscimo da precipitação pluviométrica do estado de Goiás nos meses de agosto, do período de 1977 a 2006, quando os mesmos estão sob influência dos fenômenos climáticos El Niño e La Niña. A maior diminuição da temperatura do Pacífico registrada nos meses de julho, de 1977 a 2006 , foi de $1,2{ }^{\circ} \mathrm{C}$ no ano de 1988 e não provocou chuvas no estado de Goiás, enquanto que nas fases do El Niño, o maior aumento da temperatura foi de $2,0{ }^{\circ} \mathrm{C}$ no ano de 1997, provocando uma chuva máxima diária de 0,1 mm. Durante toda a série de 1977 a 2006, a maior precipitação pluviométrica registrada em Goiás para o mês de agosto foi de $31,4 \mathrm{~mm}$, para um aquecimento das águas do Pacífico de 0,5 ${ }^{\circ} \mathrm{C}$, e a menor foi de $0,0 \mathrm{~mm}$ para uma diminuição normal de $0,4{ }^{\circ} \mathrm{C}$ da temperatura do oceano Pacífico.

Conforme demonstra a Figura 12 nos meses de setembro, de 1977 a 2006, houve uma tendência de diminuição da precipitação pluviométrica no estado de Goiás durante os episódios de La Niña e do El Niño. Na fase mais intensa de La Niña para os meses de setembro, do período histórico de 1977 a 2006, a temperatura oceânica diminuiu $1,3{ }^{\circ} \mathrm{C}(1988)$

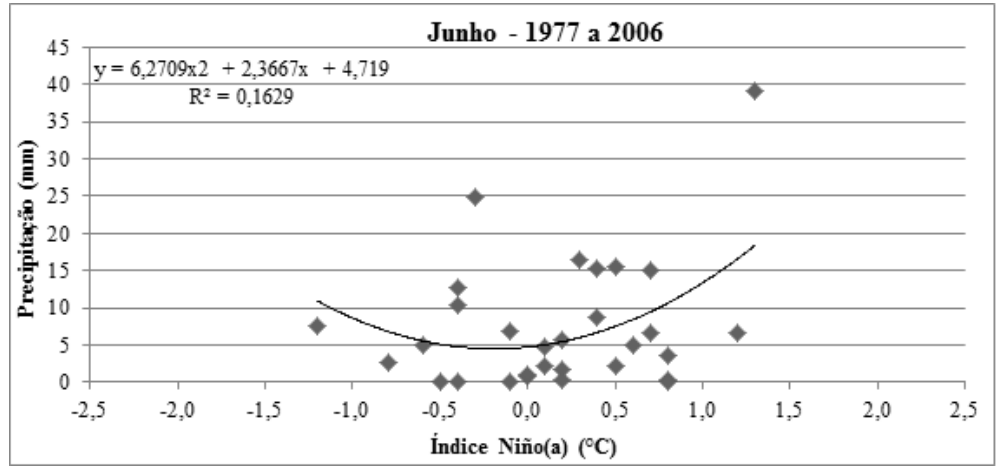

Figura 9- Dispersão em junho da Precipitação Máxima Diária Média em relação ao Índice Niño(a) do período.

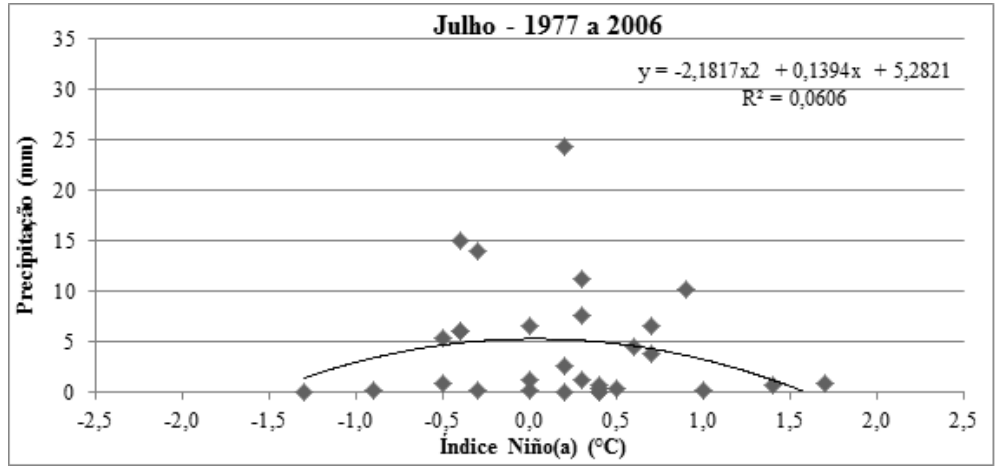

Figura 10 - Dispersão em julho da Precipitação Máxima Diária Média em relação ao Índice Niño(a) do período.

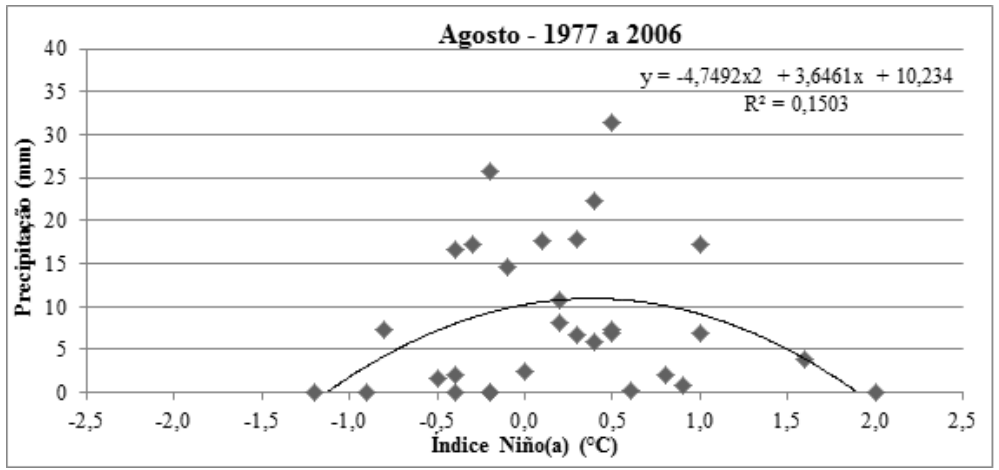

Figura 11 - Dispersão em agosto da Precipitação Máxima Diária Média em relação ao Índice Niño(a) do período. 
ocasionando uma precipitação máxima diária de 7,4 mm em Goiás. Já em períodos do El Niño a temperatura oceânica aumentou $2,2^{\circ} \mathrm{C}$ (1997), ocasionando uma precipitação máxima diária de $25,5 \mathrm{~mm}$. A precipitação máxima diária obtida no período histórico estudado foi de $36,7 \mathrm{~mm}$ (1979), para um aumento de $0,3^{\circ} \mathrm{C}$ da temperatura das águas do oceano Pacífico. Já a menor precipitação diária, no mesmo período, foi de 3,5 mm (2004), para um El Niño de $0,9^{\circ} \mathrm{C}$.

A tendência de aumento da precipitação pluviométrica em Goiás nos episódios do El Niño e La Niña durante os meses de outubro, da série histórica de 1977 a 2006, pode ser notada na Figura 13. Na fase mais forte de La Niña para outubro, de 1977 a 2006, a temperatura do oceano Pacífico diminuiu 1,6 ${ }^{\circ} \mathrm{C}$ (1988) e provocou uma precipitação máxima diária de 49,8 $\mathrm{mm}$ no estado. No episódio mais forte do El Niño durante o período histórico estudado a temperatura do oceano Pacífico aumentou $2,4{ }^{\circ} \mathrm{C}$ (1997) provocando uma precipitação máxima diária em Goiás de $52,1 \mathrm{~mm}$. A menor precipitação verificada para o período de estudo foi de $26,0 \mathrm{~mm}$ (2002), a maior foi de 53,2 $\mathrm{mm}$ (2006) e ambos eventos extremos ocorreram em períodos de intensidade moderada e fraca do El Niño, $1,3{ }^{\circ} \mathrm{C}$ e $0,9^{\circ} \mathrm{C}$, respectivamente.

Nos meses de novembro, da série de 1977 a 2006, o resfriamento das águas do Pacífico provocou, durante suas ocorrências, diminuição das chuvas em Goiás (Figura 14). A fase mais intensa de La Niña na série histórica considerada foi no ano de 1988 e a temperatura do oceano Pacífico diminuiu 1,9 ${ }^{\circ} \mathrm{C}$ provocando uma precipitação máxima diária de 45,1 mm. Nas fases do El Niño a precipitação pluviométrica em Goiás diminuiu (Figura 14). O maior aumento da temperatura das águas do Pacífico registrado nos meses de novembro, da série de 1977 a 2006 , foi de $2,5^{\circ} \mathrm{C}$ no ano de 1997 e provocou uma chuva máxima diária de 50,1 mm. Observa-se na Figura 14, que a máxima precipitação diária registrada no mês de novembro desta série foi de $65,8 \mathrm{~mm}$ no ano de 2006 sob influência moderada $\left(1,1^{\circ} \mathrm{C}\right)$ do El Niño, enquanto a mínima precipitação diária registrada no mesmo período foi de 40,6 mm (1993), em condições normais $\left(0,3^{\circ} \mathrm{C}\right)$ de temperatura do oceano Pacífico.

Conforme demonstra a Figura 15 nos meses de dezembro, de 1977 a 2006, houve uma tendência de diminuição da precipitação pluviométrica em Goiás durante os episódios de La Niña, em cuja fase mais intensa registrou diminuição de $1,9{ }^{\circ} \mathrm{C}$ (1988) na temperatura do Pacífico ocasionando uma precipitação máxima diária 52,3 mm no estado. Observa-se uma tendência média de diminuição da precipitação para o mês de dezembro, quando o mesmo está sob influência do El Niño. Em 1997 temperatura oceânica aumentou 2,5 ${ }^{\circ} \mathrm{C}$, ocasionando uma precipitação máxima diária de 55,3 mm. A precipitação máxima

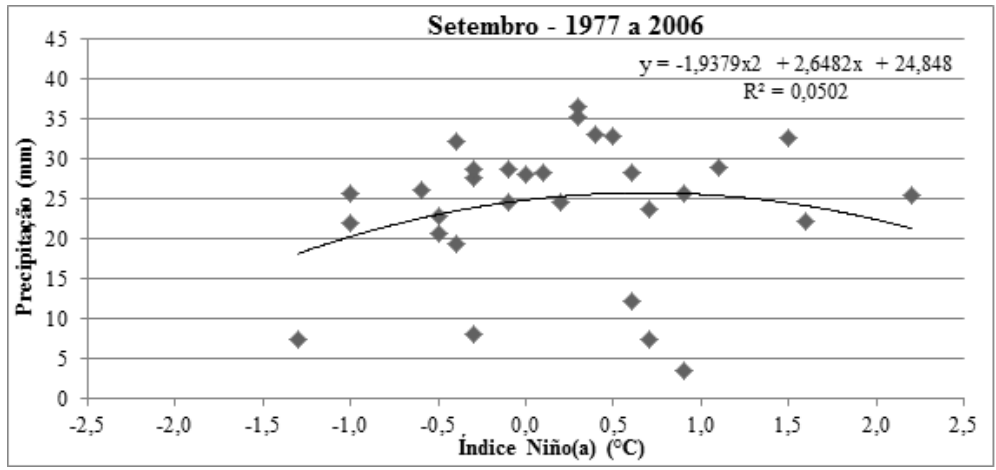

Figura 12- Dispersão em setembro da Precipitação Máxima Diária Média em relação ao Índice Niño(a) do período.

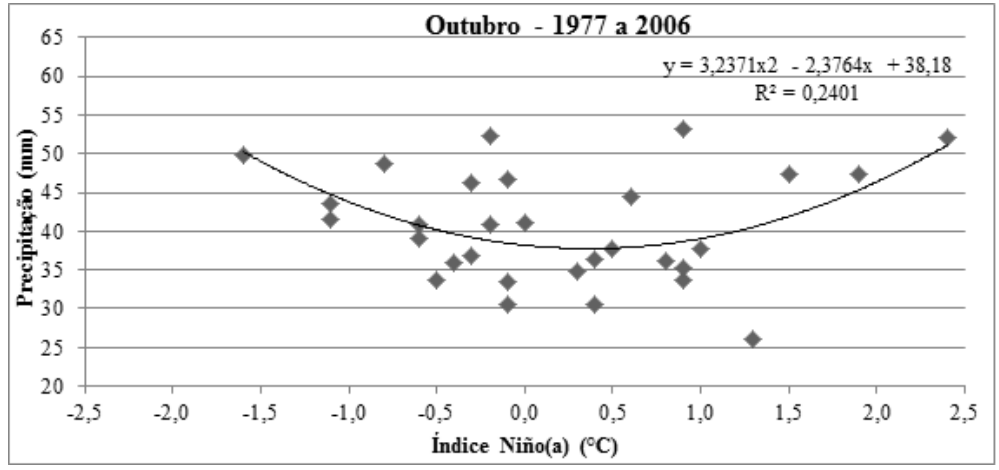

Figura 13 - Dispersão em outubro da Precipitação Máxima Diária Média em relação ao Índice Niño(a) do período. 
diária obtida no período histórico estudado foi de $75,5 \mathrm{~mm}$ (1987), para um valor normal de $-0,1$ de queda na temperatura do Pacífico. A menor precipitação diária, no mesmo período, foi de 45,5 mm (1998), para um aumento normal de $0,4^{\circ} \mathrm{C}$ na temperatura do Pacífico (Figura 15).

Segundo a Figura 16, observa-se uma média estável de precipitação, tanto nas fases de La Niña, quanto do El Niño, no período de 1977 a 2006. A fase mais intensa de La Niña para o período foi em 1999 e a temperatura do Pacífico diminuiu, em média, $1,1{ }^{\circ} \mathrm{C}$ ocasionando uma precipitação máxima diária de 66,4 mm em Goiás. O episódio mais forte do El Niño para o período foi no ano de 1997 , onde se registrou o aumento médio de $1,3{ }^{\circ} \mathrm{C}$ na temperatura do Pacífico, ocasionando uma precipitação máxima diária de $68,1 \mathrm{~mm}$ no estado (Figura 16).

A Figura 17 correlaciona, em vermelho, a redução ou aumento da temperatura do oceano Pacífico, La Niña e El Niño, respectivamente, com o volume de precipitação pluviométrica (colunas azuis) no estado de Goiás, durante a série histórica de 1977 a 2006. A fase mais intensa de La Nina, para o período de 1977 a 2006, registrou queda máxima da temperatura oceânica equivalente a $1,9{ }^{\circ} \mathrm{C}$ em 1988 , ocasionando uma precipitação máxima diária de 59,6 mm em Goiás (Figura 17). O episódio

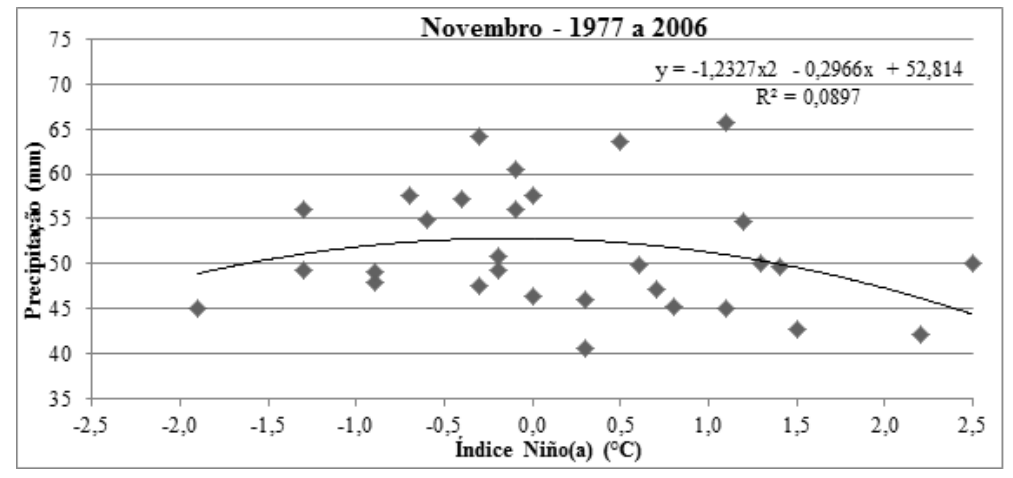

Figura 14 -Dispersão em novembro da Precipitação Máxima Diária Média em relação ao Índice Niño(a) do período.

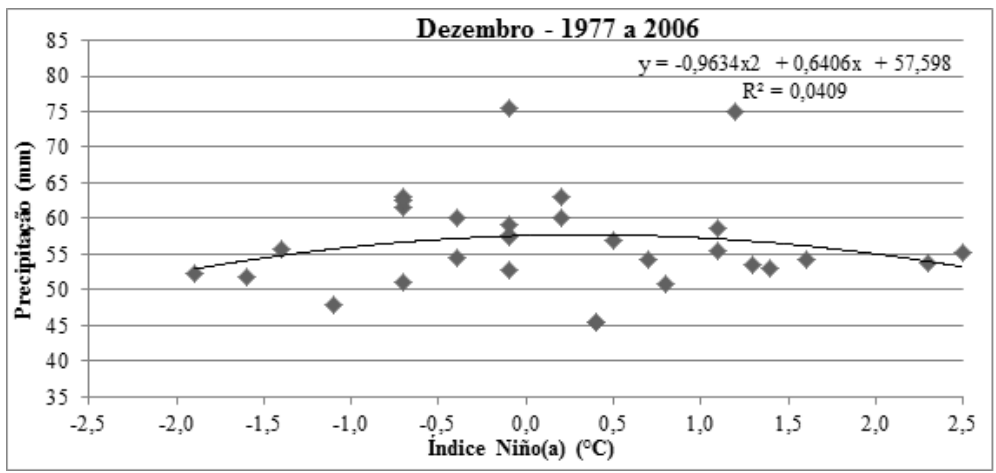

Figura 15 - Dispersão em dezembro da Precipitação Máxima Anual Média em relação ao Índice Niño(a) do período.

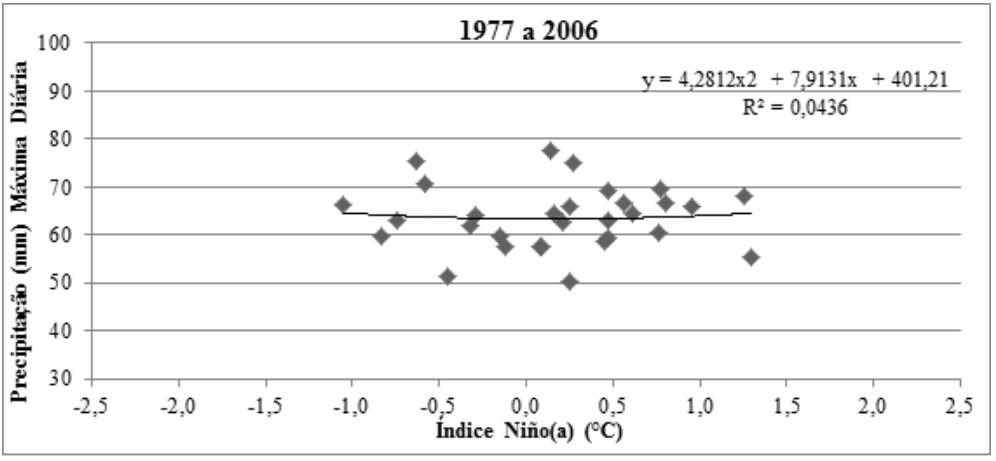

Figura 16 -Dispersão da Precipitação Máxima Diária Anual em relação ao Índice Niño(a) do período. 


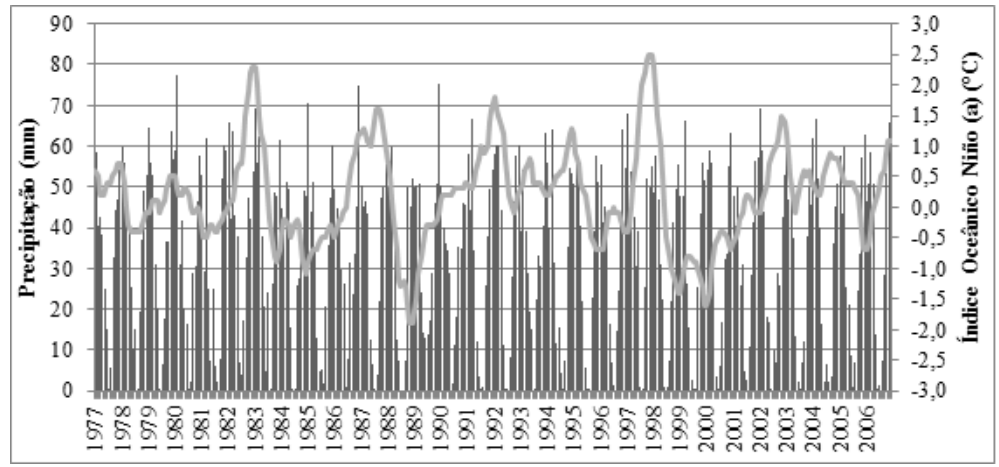

Figura 17 -Dispersão da Precipitação Máxima Diária Anual em relação ao Índice Niño(a) do período.

Tabela 3 -Análise estatística da precipitação máxima diária do estado de Goiás.

\begin{tabular}{lccccccccccccc}
\hline & Jan & Fev & Mar & Abr & Mai & Jun & Jul & Ago & Set & Out & Nov & Dez & Anual \\
\hline \hline Máximo & 70,7 & 77,6 & 66,7 & 50,9 & 37,9 & 39,1 & 24,3 & 31,4 & 36,7 & 53,2 & 65,8 & 75,5 & 461,3 \\
Média & 55,8 & 49,6 & 52,1 & 35,4 & 18,6 & 7,4 & 4,4 & 8,5 & 24,1 & 40,5 & 51,4 & 56,6 & 404,2 \\
Mediana & 55,7 & 47,2 & 51,2 & 36,0 & 16,7 & 5,0 & 1,3 & 6,9 & 25,7 & 40,0 & 49,8 & 55,3 & 396,3 \\
Mínimo & 39,3 & 29,4 & 31,0 & 18,2 & 3,7 & 0,0 & 0,0 & 0,0 & 3,5 & 26,0 & 40,6 & 45,4 & 360,3 \\
Desvio Padrão & 8,0 & 9,9 & 9,1 & 7,9 & 7,5 & 8,6 & 5,8 & 8,7 & 8,6 & 7,1 & 6,7 & 6,9 & 27,2 \\
\hline
\end{tabular}

mais intenso do El Niño, durante os anos de 1977 a 2006, ocorreu no final do ano de 1997 e a temperatura do Pacífico aumentou $2,5^{\circ} \mathrm{C}$ ocasionando uma precipitação máxima diária de $68,1 \mathrm{~mm}$ (Figura 17).

$\mathrm{Na}$ análise estatística (Tabela 3) verifica-se que a precipitação máxima diária do estado de Goiás foi obtida no mês de fevereiro $(77,6 \mathrm{~mm})$ de 1980, quando o Índice Niño estava em $0,3^{\circ} \mathrm{C}$ (Figura 5). A tendência central (média), que é o centro de um grupo de números em uma distribuição estatística, para os valores de precipitação máxima diária, mostrou uma maior proximidade com os valores máximos nos meses chuvosos (outubro a abril) em relação aos meses secos (maio a setembro), que tiveram maior proximidade com os valores mínimos. Nos meses mais úmidos, verifica-se que a mediana ficou muito próxima da média e se distanciando da mesma nos meses mais secos. A medida do grau de dispersão dos valores em relação ao seu valor médio mostra que, em média, nos meses de maior precipitação máxima diária o desvio padrão foi maior que nos meses com menores valores. O maior desvio padrão foi obtido no mês de fevereiro $(9,9)$, considerado mês chuvoso, e o menor desvio padrão foi obtido no mês de julho $(5,8)$, considerado mês seco.

\section{CONCLUSÕES}

Os resultados deste trabalho demonstram que os fenômenos climáticos denominados Niños afetam a dinâmica climática ocasionando mudanças significativas no regime das chuvas máximas diárias, podendo aumentar ou diminuir o volume de precipitação em períodos do El Niño e La Niña, respectivamente. Nesse sentido, durante o período de 1977 a 2006 os episódios do El Niño se manifestaram, com intensidade fraca, moderada ou forte, nos anos de 1977, 1982, 1986, 1987, 1991, 1994, 1997, 2002, 2006 e as fases de La Niña foram registradas nos anos de 1984, 1988, 1995, 1998, 1999 e 2000.

O episódio mais intenso do El Niño aumentou a temperatura das águas do oceano Pacífico em $2,5^{\circ} \mathrm{C}$ nos meses de novembro e dezembro da série histórica de 1977 a 2006, provocando uma precipitação máxima diária de $50,1 \mathrm{~mm}$ e 55,3 $\mathrm{mm}$, respectivamente, no estado de Goiás. Quanto à atuação de La Niña, este estudo revelou que no ano de 1988 a temperatura das águas do Pacífico diminuiu $1,9^{\circ} \mathrm{C}$ registrando, portanto, a intensidade mais forte do fenômeno durante o período de 1977 a 2006 e ocasionando uma precipitação máxima diária de 52,3 $\mathrm{mm}$ em Goiás.

Verificou-se com esta pesquisa que a média de precipitação diária do estado corresponde a 33,7 mm. A máxima precipitação diária registrada em Goiás foi de $77,6 \mathrm{~mm}$ no ano de 1980 , sob temperatura normal do oceano Pacífico $\left(0,3{ }^{\circ} \mathrm{C}\right)$. $\mathrm{O}$ estudo também demonstra que nos meses de junho, julho e agosto da série de 1977 a 2006, em fases moderadas de La Niña (média de $-1,23{ }^{\circ} \mathrm{C}$ ) no estado de Goiás, não houve registro de precipitação. Concluí-se, portanto, que os fenômenos climáticos El Niño e La Niña exerceram influência relativa e sazonal na precipitação pluviométrica máxima diária do estado de Goiás.

\section{AGRADECIMENTOS}

Os autores agradecem à CPRM/SGB (Companhia de Pesquisa de Recursos Minerais / Serviço Geológico do Brasil - 
empresa pública de pesquisa do Ministério de Minas e Energia) pelo fomento que viabilizou o desenvolvimento deste trabalho.

\section{BIBLIOGRAFIA}

IBGE. (2010). Estatística Populacional - Censo 2010. Disponível em <http://www.ibge.gov.br/cidadesat/link. php?uf=to $>$. Acesso 10/2011.

NAGHETTINI \& PINTO. Hidrologia Estatística. Belo Horizonte: CPRM, 2007. 552p.

PEREIRA, R. C. G.; BRAGA, C. C.; PAZ, R. L. F. Estudo da Pluviometria no Estado de Goiás. Aplicando a Técnica de Análise Fatorial em Componentes Principais. In: CONGRESSO BRASILEIRO DE METEOROLOGIA, 16, 2010, Belém-PA. Anais eletrônicos. Belém: SBMET, 2010. Disponível em: <http://www.cbmet2010.com/anais/ artigos/363_65246.pdf>. Acesso em: 29 ago. 2011.

PINTO, E. J. de A.; AZAMBUJA, A. M. S. de; FARIAS, J. A. M.; SAlGUEIRO, J. P.de B.; PICKBRENNER, K. (Coords.). (2011). Atlas pluviométrico do Brasil: isoietas mensais, isoietas trimestrais, isoietas anuais, meses mais secos, meses mais chuvosos, trimestres mais secos, trimestres mais chuvosos. Brasília: CPRM, 2011. 1 DVD.
Escala 1.5:000.000. Equipe Executora: Andressa M. S. de Azambuja; Margarida R. da Costa; Carlos Eduardo de O. Dantas; José Alexandre M. Farias; Érica C. Machado; Francisco F. N. Marcuzzo; Vanesca S. Medeiros; Denise C. de Rezende Melo; Jean R. da S. do Nascimento; Paulo de Tarso R. Rodrigues; André Luis M. R. dos Santos; Adriana B. Weschenfelder; Sistema de Informação Geográfica-SIG - versão 2.0 - atualizada em novembro/2011; Programa Geologia do Brasil; Levantamento da Geodiversidade.

SALES, N.; REBELLO, E.; FÁTIMA, J. As maiores "cheias" e "secas" no Amazonas e as influências dos fenômenos "El Niño", "La Niña", “ODP” e "OMA”. In: CONGRESSO BRASILEIRO DE METEOROLOGIA, 16, 2010, BelémPA. Anais eletrônicos. Belém: SBMET, 2010. Disponível em:<http://www.cbmet2010.com/anais/artigos/659_97635. pdf $>$. Acesso em: 26 ago. 2011.

SOUSA, A. J. S.; FERREIRA, E. A.; SOUSA, J. R. A.; ROLIM, P. A. M. A Oscilação Decadal do Pacífico e sua Influência na Precipitação de Goiânia - GO. In: CONGRESSO BRASILEIRO DE METEOROLOGIA, 16, 2010, BelémPA. Anais eletrônicos. Belém: SBMET, 2010. Disponível

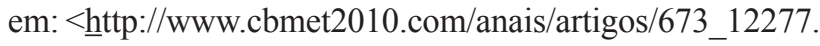
pdf $>$. Acesso em: 26 ago. 2011. 